\title{
CHRONIC OBSTRUCTIVE PULMONARY DISEASE
}

\section{Influence of lung volume reduction surgery (LVRS) on health related quality of life in patients with chronic obstructive pulmonary disease}

\author{
R S Goldstein, T R J Todd, G Guyatt, S Keshavjee, T E Dolmage, S van Rooy, B Krip, \\ F Maltais, P LeBlanc, S Pakhale, T K Waddell
}

Thorax 2003;58:405-410

See end of article for authors' affiliations

Correspondence to: Dr R S Goldstein, West

Park Healthcare Centre, 82 Buttonwood Avenue,

Toronto, Ontario, Canada M6M 2J5;

rgoldstein@westpark.org

Revised version received 11 December 2002

Accepted for publication

17 January 2003
Background: The clinical value of LVRS has been questioned in the absence of trials comparing it with pulmonary rehabilitation, the prevailing standard of care in COPD. Patients with heterogeneous emphysema are more likely to benefit from volume reduction than those with homogeneous disease. Disease specific quality of life is a responsive interpretable outcome that enables health professionals to identify the magnitude of the effect of an intervention across several domains.

Methods: Non-smoking patients aged $<75$ years with severe COPD (FEV $1<40 \%$ predicted, FEV 1 /FVC $<0.7$, hyperinflation, and evidence of heterogeneity were randomised to surgical or control groups after pulmonary rehabilitation and monitored at 3 month intervals for 12 months with no crossover between the groups. The primary outcome was disease specific quality of life as measured by the Chronic Respiratory Questionnaire (CRQ). Treatment failure was defined as death or functional decline (fall of 1 unit in any two domains of the CRQ). Secondary outcomes included pulmonary function and exercise capacity.

Results: LVRS resulted in significant between group differences in each domain of the CRQ at 12 months (change of 0.5 represents a small but important difference): dyspnoea 1.9 (95\% confidence interval (Cl) 1.3 to $2.6 ; p<0.0001)$; emotional function $1.5(95 \% \mathrm{Cl} 0.9$ to $2.1 ; \mathrm{p}<0.0001)$; fatigue $2.0(95 \% \mathrm{Cl} 1.4$ to $2.6 ; \mathrm{p}<0.0001)$; mastery 1.8 (95\% Cl 1.2 to $2.5 ; \mathrm{p}<0.0001)$. In the control group one of 27 patients died and 16 experienced functional decline over 12 months. In the surgical group four of 28 patients died and three experienced functional decline (hazard ratio $=3.1(95 \% \mathrm{Cl} 1.3$ to 7.6; $p=0.01)$. Between group improvements $(p<0.05)$ in lung volumes, flow rates, and exercise were sustained at 12 months (RV $-47 \%$ predicted $(95 \% \mathrm{Cl}-71$ to $-23 ; \mathrm{p}=0.0002) ; \mathrm{FEV}, 0.3 \mathrm{I}(95 \% \mathrm{Cl} 0.1$ to $0.5 ; p=0.0003)$; submaximal exercise $7.3 \mathrm{~min}(95 \% \mathrm{Cl} 3.9$ to $10.8 ; \mathrm{p}<0.0001)$; 6 minute walk 66 metres (95\% Cl 32 to $101 ; p=0.0002)$.

Conclusions: In COPD patients with heterogeneous emphysema, LVRS resulted in important benefits in disease specific quality of life compared with medical management, which were sustained at 12 months after treatment. a ung volume reduction surgery (LVRS) has been introduced as a management option for patients with severe chronic obstructive pulmonary disease (COPD). ${ }^{1-4}$ Surgical removal of the most compliant lung tissue improves airflow and reduces the work of breathing in the remaining lung. ${ }^{56}$ Despite numerous reports describing clinical benefits, the overall value of this procedure has been questioned in the absence of prospective randomised controlled trials that compare LVRS with the prevailing standard of care-namely, pulmonary rehabilitation. ${ }^{78}$ Such trials enable selection criteria and pulmonary rehabilitation to be standardised, as well as ensuring that those responsible for outcome measures are unaware of the group allocation of their subjects. ${ }^{9-11}$

Three randomised controlled trials have provided evidence for the efficacy of LVRS, but all have important limitations. Pompeo et al $^{12}$ compared LVRS with rehabilitation with only short term follow up; in a study by Criner et al $^{13}$ significance was only reached when crossover patients were included; and Geddes et al $^{14}$ reported improvements in pulmonary function and exercise tolerance with no restriction on the pattern or distribution of the emphysema among the subjects enrolled. After the first 15 subjects the entry criteria were modified to exclude those with the most severe impairments (transfer factor $<30 \%$ predicted and shuttle walk test $<150$ metres). Quality of life was measured with a general rather than a disease specific health questionnaire. Last year the National
Emphysema Treatment Trial Research Group cautioned that patients with forced expiratory volume in 1 second $\left(\mathrm{FEV}_{1}\right)$ below $20 \%$ predicted and either a carbon monoxide transfer factor below $20 \%$ predicted or a homogeneous distribution of emphysema were at high risk for death after surgery. ${ }^{15}$ Those who did survive had only small changes in pulmonary function and exercise capacity with no improvements in their quality of well being compared with medically treated patients.

In this report we summarise the results of a prospective randomised controlled trial of LVRS undertaken between 1997 and 2001 in which the primary outcome was disease specific health related quality of life, chosen because of its increased responsiveness and interpretability over general health outcomes. Only patients who were clinically stable and who had severe emphysema of heterogeneous distribution were enrolled. We report the results of 55 patients randomised to receive LVRS or continuing medical care following an initial 6 weeks of rehabilitation.

\section{METHODS}

\section{Trial design}

Patients were referred by respiratory specialists or family physicians to a lung volume reduction clinic. A pulmonary specialist, a thoracic surgeon, and the trial coordinator 
reviewed all patients at each of their assessment or follow up visits. After patients were informed of the risks and potential benefits of the clinical trial, they signed a consent form approved by the University of Toronto ethics review board.

Entry criteria included age $<75$ years, severe stable COPD $\left(\mathrm{FEV}_{1}<40 \%\right.$ predicted, $\left.\mathrm{FEV}_{1} / \mathrm{FVC}<0.7\right)$, hyperinflation at total lung capacity (TLC) (TLC by plethysmography $>120 \%$ predicted), and gas trapping at TLC (TLC plethysmography minus TLC gas dilution >1.5 l), evidence of heterogeneity on a computed tomographic (CT) or ventilation/perfusion scan. In addition, patients were non-smokers (quit for more than 6 months), were receiving optimal pharmacological management, and had had no exacerbations for at least 6 weeks.

Exclusion criteria included asthma, previous lung surgery, pleural disease, general contraindications to surgery, coexisting symptomatic disease that might limit exercise tolerance or health related quality of life, inability to attend for rehabilitation or follow up, pulmonary hypertension (systolic pulmonary arterial pressure (PAP) $>42 \mathrm{~mm} \mathrm{Hg}$ or mean PAP $>35 \mathrm{~mm} \mathrm{Hg})$, hypercapnia $\left(\mathrm{PaCO}_{2}>6.6 \mathrm{kPa}\right)$, or homogeneous disease.

All patients were enrolled in a 6 week programme of rehabilitation that included supervised exercises, education, and psychosocial support. ${ }^{16}$ During this time their medications were optimised. A physician and surgeon reassessed those wishing to proceed and made the final decision regarding eligibility. The physician and surgeon remained unaware of the arm to which the patient would be allocated. They advised the coordinator of the patient's eligibility. The patient was then allocated to surgery or ongoing medical treatment according to the randomisation code (random numbers table, block randomisation in groups of four). This procedure ensured concealment of randomisation. Research assistants who were blind to the patient's group allocation conducted all outcome assessments at 3, 6, 9, and 12 months after randomisation.

\section{Initial assessment and follow up}

At their initial visit patients underwent full pulmonary function measures (spirometric lung volumes and flow rates, plethysmographic volumes, single breath transfer factor for carbon monoxide, single breath gas dilution alveolar volume, and maximal inspiratory and expiratory pressures). ${ }^{17}{ }^{18}$ Arterial blood gas tensions were measured with the subjects resting, seated, and breathing room air for 20 minutes. All subjects underwent electrocardiography and two dimensional echocardiography. If the echocardiogram was suggestive of pulmonary hypertension or if there was any history of ischaemic heart disease, subjects also underwent cardiac catheterisation.

Imaging consisted of a postero-anterior and lateral chest radiograph, a high resolution $\mathrm{CT}$ scan, and a ventilation/ perfusion (V/Q) scan. The CT scan (GE Medical Systems Lightspeed Ultra, Milwaukee, Wisconsin, USA) included thin sections and contiguous $10 \mathrm{~mm}$ sections at full inspiration. Emphysema was reported by a radiologist for each lung zone (upper, middle and lower) for both lungs using a six point scale (none, mild, mild to moderate, moderate, moderately severe, and severe). Heterogeneity by CT scanning was defined as a difference of more than two points between the upper and lower lung zone emphysema scores. The ventilation/perfusion scan (Xennamatic 3000D Xenon Gas Delivery System, Diversified Diagnostic Products-Houston Texas, USA and Apex SP 4 Elscint using macro-aggregated albumin with technetium$99 \mathrm{~m}$ ) was reported by lung zone (upper, middle and lower) for both lungs, and perfusion was reported as a percentage of the total perfusion for both lungs by side. Ventilation was shown graphically for each of the six zones and reported numerically as: wash in (percentage of the total xenon ventilation wash in for both lungs), wash out (units per second for each zone), and half life (seconds for each zone). Heterogeneity by V/Q was decided from identified differences between zones. The radiologists reporting both CT and V/Q scans were unaware of the patient's clinical details.

Exercise was measured at the beginning of the rehabilitation programme using the 6 minute walking test according to standardised criteria. ${ }^{19}$ Three tests were carried out initially. The test was repeated at the end of rehabilitation and immediately before randomisation. Incremental and submaximal constant power exercise tests were measured in a standardised manner ${ }^{20}$ immediately before randomisation.

Disease specific health related quality of life (HRQL) was measured using the Chronic Respiratory Questionnaire $(\mathrm{CRQ})^{21}$ by domains of dyspnoea, emotional function, mastery, and fatigue.

\section{Outcome measures}

The primary outcome measure was disease specific quality of life (CRQ). The CRQ is a disease specific measure of HRQL which focuses on four domains: dyspnoea, fatigue, emotional function, and mastery (patients' sense of being in control of their lives and their health problem). The CRQ has been widely used in patients with chronic lung disease and experience has provided strong evidence of both validity (it really measures disease specific HRQL) and responsiveness (the CRQ detects important changes even if they are small). Extensive data suggest that the minimal clinically important difference (MCID) in change in CRQ score is 0.5; a change of 1.0 is thus twice the MCID and represents a moderate effect. ${ }^{22}$ Treatment failure was defined as death or functional decline (a consistent reduction of $>1$ unit in any two domains in the CRQ from which they did not recover). Secondary measures included the 6 minute walking distance, submaximal cycle endurance time, and measures of pulmonary function $\left(\mathrm{FEV}_{1}\right.$, $\mathrm{FEV}_{\mathrm{l}} / \mathrm{FVC}$, residual volume (RV), functional residual capacity (FRC), and TLC).

\section{Surgery}

Surgery was performed by video-assisted thoracic surgery (VATS) or, less often, by median sternotomy at the discretion of the surgeon. The extent and location of the resection was determined preoperatively from the CT and V/Q scans and confirmed intraoperatively by the surgeon based on the macroscopic appearance of the lung and its deflation characteristics. An attempt was made to remove $20-30 \%$ of the lung volume. Whenever possible, bilateral lung reduction was effected. With VATS procedures most patients were positioned in the decubitus position and the stability of the patient as well as the size of the air leak was evaluated before proceeding to the second side. Mechanical staplers and bovine pericardium were used routinely and pleural tents were used occasionally. Patients were extubated in the operating room immediately after regaining consciousness.

\section{Postoperative management}

Patients remained in the surgical recovery unit until they were clinically stable after which they were transferred to the thoracic surgical ward. Principles of management included patient controlled epidural analgesia, early mobilisation, care by an experienced physiotherapist and nursing team, minimal or no suction applied to the chest tubes, careful fluid balance, and arterial blood gas monitoring. Once stable, patients were offered a brief (1-2 week) period of rehabilitation or discharged directly home. A few patients were discharged with chest tubes attached to Heimlich valves.

\section{Analysis of data}

Mean values for each variable were calculated and expressed as mean (SE) and mean (95\% confidence intervals, CI) unless stated otherwise. All subjects were evaluated at baseline and again at 3, 6, 9, and 12 months. The time to treatment failure 


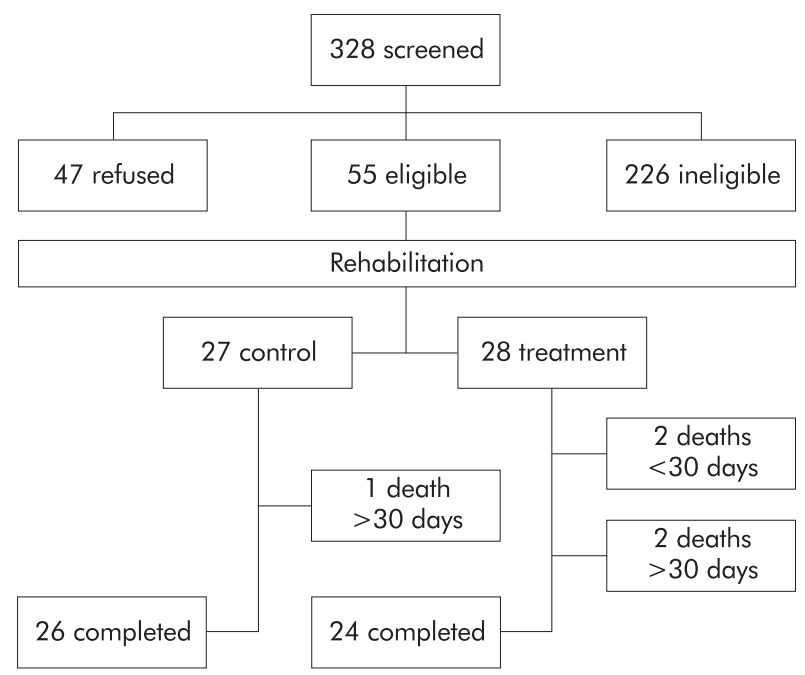

Figure 1 Schematic diagram of the trial design showing randomisation and trial completion.

(functional decline, missing data due to treatment complications, or death) was displayed graphically. The observed time to the event was censored at the end of the follow up period (12 months). A proportional hazards model was used to determine whether the surgical and control groups followed the same function. The results were summarised using a hazard ratio with $95 \% \mathrm{CI}$ around the estimate.

For each continuous outcome variable we conducted a repeated measures analysis of variance using the baseline value as a covariate and examining the effect of time, treatment, and the interaction between the two. To provide an estimate of the magnitude and precision of the effect of treatment, we used the mean difference between treatment and control at the final follow up, adjusted for the baseline score, and calculated a 95\% CI around this difference.

\section{RESULTS}

\section{Enrollment}

328 subjects were screened for eligibility and 55 were randomised after rehabilitation (28 surgery and 27 control; fig 1). Enrollment to the trial was declined by 47 subjects. Reasons for exclusion were: inappropriate pulmonary disease $(n=64)$, disease severity $(n=63)$, associated medical conditions $(n=27)$, homogeneous disease $(n=49)$, surgical contraindications $(n=14)$, age $(n=5)$, and smoking $(n=4)$.

\section{Baseline measures}

Demographic and pulmonary function measures reflected the similarity of age, sex, airflow obstruction, hyperinflation, gas trapping at TLC, and arterial blood gas tensions among those eligible, those who refused, and those who were ineligible for enrollment to the study (table 1). The 55 subjects with heterogeneous disease accepted for the study did not differ in baseline characteristics from the 49 subjects with homogeneous disease $(p>0.1)$. Subjects assigned to the surgical and non-surgical groups had similar baseline pulmonary function (table 2). There were no between group differences in age (65 (10) $v 65$ (2) years), height (169 (2) v $167(2) \mathrm{cm})$, weight (65 (2) $v 70(2) \mathrm{kg})$, resting $\mathrm{PaO}_{2}(9.1(0.3) v 9.6(0.3) \mathrm{kPa})$, or resting $\mathrm{PaCO}_{2}(5.7$ (0.1) v $5.9(0.1) \mathrm{kPa})$.

\section{Deaths and complications}

Bilateral LVRS was carried out in all subjects assigned to the surgical group except eight who underwent unilateral LVRS (two had homogeneity on the non-operated side and six had limiting adhesions at the time of operation). In the control group one subject died of respiratory failure 117 days after randomisation. In the surgical group there were two deaths within 30 days of surgery (days 7 and 15) and a further two during the 12 month follow up period ( 285 and 334 days after surgery), all of which were attributable to respiratory failure. There were four other serious complications (two subjects required prolonged ventilation, one of whom sustained a nonfatal cardiac arrest, one had significant bleeding, and one had

Table 1 Eligibility status by pulmonary function results $(n=328)$

\begin{tabular}{|c|c|c|c|}
\hline & Eligible $(n=55)$ & Ineligible $(n=226)$ & Declined $(n=47)$ \\
\hline Age (years) & $64.9(0.91)$ & $64.1(0.53)$ & $64.1(1.12)$ \\
\hline $\operatorname{Sex}(M / F)$ & $33 / 22$ & $138 / 88$ & $28 / 19$ \\
\hline $\mathrm{FEV}_{1}$ (observed) & $0.7(0.03)$ & $0.8(0.03)$ & $0.9(0.06)$ \\
\hline $\mathrm{FEV}_{1}$ (\% predicted) & $32(1.38)$ & $34(1.07)$ & $36(2.39)$ \\
\hline FVC (observed) & $2.5(0.12)$ & $2.5(0.07)$ & $2.6(0.16)$ \\
\hline FVC (\% predicted) & 73 (2.79) & $74(1.75)$ & $79(3.67)$ \\
\hline $\mathrm{FEV}_{1} / \mathrm{FVC}$ (observed) & $32(1.23)$ & $33(0.67)$ & $32(1.20)$ \\
\hline $\mathrm{FEV}_{1} / \mathrm{FVC}$ (\% predicted) & 45 (1.65) & $47(0.93)$ & 45 (1.71) \\
\hline FRC (observed) & $6.4(0.21)$ & $5.8(0.13)$ & $5.9(0.31)$ \\
\hline FRC ( $\%$ predicted) & $195(4.64)$ & $183(3.80)$ & $184(8.27)$ \\
\hline RV (observed) & $5.3(0.19)$ & $4.9(0.12)$ & $5.0(0.27)$ \\
\hline RV (\% predicted) & $240(7.89)$ & $236(5.68)$ & $236(12.1)$ \\
\hline TLC (observed) & $8.1(0.24)$ & $7.9(0.14)$ & $8.0(0.34)$ \\
\hline TLC (\% predicted) & $146(2.64)$ & $142(1.73)$ & $147(4.13)$ \\
\hline $\mathrm{TLC}_{\mathrm{He}}$ (observed) & $4.1(0.17)$ & $4.3(0.10)$ & $4.6(0.23)$ \\
\hline $\mathrm{TLC}_{\mathrm{He}}$ (\% predicted) & $73(2.18)$ & 77 (1.31) & $84(3.28)$ \\
\hline Trapped gas & $4.0(0.19)$ & $3.6(0.12)$ & $3.3(0.32)$ \\
\hline TLco (observed) & $7.2(0.34)$ & $9.4(0.63)$ & $8.8(0.65)$ \\
\hline TLCO (\% predicted) & $35(1.63)$ & $42(2.43)$ & $38(2.51)$ \\
\hline $\mathrm{MIP}_{\mathrm{RV}}\left(-\mathrm{cm} \mathrm{H} \mathrm{H}_{2} \mathrm{O}\right)^{*}$ & $-54(4.50)$ & $-47.2(2.94)$ & $-48.3(5.44)$ \\
\hline $\mathrm{MEP}_{\mathrm{TLC}}\left(\mathrm{cm} \mathrm{H} \mathrm{H}_{2} \mathrm{O}\right)$ * & $87.9(5.16)$ & $86.5(4.90)$ & $76.5(6.54)$ \\
\hline $\mathrm{PaO}_{2}(\mathrm{kPa})$ & $9.3(0.2)$ & $8.9(0.1)$ & $9.2(0.4)$ \\
\hline $\mathrm{PaCO}_{2}(\mathrm{kPa})$ & $5.9(0.1)$ & $6.0(0.1)$ & $5.6(0.2)$ \\
\hline $\mathrm{SaO}_{2}(\%)$ & $93.3(0.36)$ & $91.3(0.43)$ & $89.1(3.21)$ \\
\hline
\end{tabular}

$\mathrm{FEV}_{1}=$ forced expiratory volume in 1 second; $F V C=$ forced vital capacity; $F R C=$ functional residual capacity; $\mathrm{RV}=$ residual volume; $\mathrm{TLC}=$ total lung capacity; $\mathrm{TLCO}=$ carbon monoxide transfer factor; $\mathrm{MIP}=$ maximum inspiratory pressure; $\mathrm{MEP}=$ maximum expiratory pressure; $\mathrm{PaO}_{2}, \mathrm{PaCO}_{2}=$ arterial oxygen and carbon dioxide tensions; $\mathrm{SaO}_{2}=$ arterial oxygen saturation.

Values are mean (SE)

*MIP and MEP only available from rehabilitation and baseline datasets; no screening data available. 
Table 2 Pulmonary function in both groups at baseline and 3, 6, 9 and 12 months $†$

\begin{tabular}{|c|c|c|c|c|c|c|c|c|c|c|}
\hline \multirow[b]{2}{*}{ Parameter } & \multicolumn{2}{|l|}{ Baseline } & \multicolumn{2}{|l|}{3 months } & \multicolumn{2}{|l|}{6 months } & \multicolumn{2}{|l|}{9 months } & \multicolumn{2}{|l|}{12 months } \\
\hline & Surgical & Control & Surgical & Control & Surgical & Control & Surgical & Control & Surgical & Control \\
\hline TLC ( $\%$ pred) & $142(4)$ & $151(5)$ & $129(4)$ * & $151(4)$ & $133(4)^{*}$ & $150(4)$ & $135(4)^{*}$ & $148(4)$ & $134(4)^{*}$ & $149(4)$ \\
\hline FRC (\% pred) & $193(8)$ & 205 (9) & $162(11)^{*}$ & $207(10)$ & $167(11)^{*}$ & $208(10)$ & $170(11)^{*}$ & 212 (10) & $171(11)^{*}$ & $212(10)$ \\
\hline RV (\% pred) & 228 (10) & 253 (13) & $184(9)^{*}$ & $235(8)$ & $191(8)^{*}$ & $236(8)$ & $195(9)^{*}$ & $241(8)$ & $192(9)^{*}$ & $239(8)$ \\
\hline FVC (I) & $2.3(0.2)$ & $2.5(0.2)$ & $2.9(0.1)^{*}$ & $2.4(0.1)$ & $3.0(0.1)^{*}$ & $2.3(0.1)$ & $2.9(0.1)^{*}$ & $2.4(0.1)$ & $2.9(0.1)^{*}$ & $2.2(0.1)$ \\
\hline FVC $(\%$ pred $)$ & 71 (5) & $73(3)$ & $88(3)^{*}$ & $77(3)$ & $89(3)^{*}$ & $72(3)$ & $89(3)$ * & $75(3)$ & $88(3)^{*}$ & $70(3)$ \\
\hline $\mathrm{FEV}_{1}$ (I) & $0.8(0.1)$ & $0.7(0.0)$ & $1.0(0.1) *$ & $0.7(0.1)$ & $1.1(0.1)^{*}$ & $0.7(0.1)$ & $1.0(0.1)^{*}$ & $0.7(0.2)$ & $1.0(0.1)^{*}$ & $0.7(0.1)$ \\
\hline $\mathrm{FEV}_{1}$ (\% pred) & $33(3)$ & $32(2)$ & $45(2)^{*}$ & $33(2)$ & $45(2)^{*}$ & $31(2)$ & $44(2)^{*}$ & $32(2)$ & $41(2)^{*}$ & $30(2)$ \\
\hline $\mathrm{FEV}_{1} / \mathrm{FVC}(\%)$ & $33(2)$ & $32(2)$ & $37(1)^{*}$ & 31 (1) & $36(1)^{*}$ & 30 (1) & $35(1)^{*}$ & 30 (1) & $33(1)^{*}$ & 30 (1) \\
\hline $\mathrm{V}_{50}(\mathrm{l} / \mathrm{s})$ & $0.31(0.03)$ & $0.30(0.02)$ & $0.42(0.03)^{*}$ & $0.29(0.02)$ & $0.44(0.03)^{*}$ & $0.26(0.02)$ & $0.37(0.03)^{*}$ & $0.25(0.02)$ & $0.35(0.03)^{*}$ & $0.24(0.02)$ \\
\hline $\mathrm{V}_{25}(\mathrm{l} / \mathrm{s})$ & $0.18(0.02)$ & $0.15(0.01)$ & $0.19(0.01)$ & $0.17(0.01)$ & $0.20(0.01)^{*}$ & $0.15(0.01)$ & $0.17(0.01)$ & $0.14(0.01)$ & $0.17(0.01)^{*}$ & $0.14(0.01)$ \\
\hline VA (\% pred) & $74(3)$ & $73(3)$ & $78(2)$ & $75(2)$ & $77(2)$ & $78(2)$ & $78(2)$ & $75(2)$ & $77(2)$ & $74(2)$ \\
\hline TLCO (\% pred) & $35(2)$ & $38(2)$ & $34(2)$ & $36(2)$ & $36(2)$ & $32(2)$ & $37(2)$ & $33(2)$ & $37(2)$ & $33(2)$ \\
\hline $\mathrm{MIP}_{\mathrm{RV}}\left(\mathrm{cm} \mathrm{H} \mathrm{H}_{2} \mathrm{O}\right)$ & $-57(5)$ & $-48(5)$ & $-62(4)^{*}$ & $-47(4)$ & $-66(4)^{*}$ & $-53(4)$ & $-64(4)$ & $-53(4)$ & $-63(4)$ & $-53(4)$ \\
\hline $\mathrm{MEP}_{\mathrm{TLC}}\left(\mathrm{cm} \mathrm{H} \mathrm{H}_{2} \mathrm{O}\right)$ & $82(7)$ & $88(8)$ & $92(9)$ & $75(9)$ & $91(9)^{*}$ & $66(9)$ & $84(9)$ & $79(9)$ & $102(9)$ & $89(9)$ \\
\hline 6 min walk $(\mathrm{m})$ & $387(15)$ & $372(17)$ & $373(13)$ & $356(12)$ & $403(13)^{*}$ & $346(12)$ & $400(13)^{*}$ & $340(12)$ & $389(13)^{*}$ & $323(12)$ \\
\hline
\end{tabular}

a sternal dehiscence). Other complications during hospitalisation for surgery included prolonged air leakage $>7$ days $(n=10)$ (one subject required re-operation for air leak), benign dysrrythmias $(n=6)$, respiratory tract infections $(n=6)$, transient confusion $(n=6)$, small bowel ileus $(n=2)$, vocal cord dysfunction $(n=2)$, and transient ischaemic attack $(n=1)$. After discharge from hospital there were four subsequent admissions in the surgical group (colitis, pneumonia, respiratory failure, empyema) and none in the control group. The only morbidities encountered during the 12 month follow up period were ischaemic heart disease (one surgical and one control subject) and respiratory infections (30 surgical and 35 control subjects).

\section{Primary outcomes}

A significant treatment effect in favour of lung volume reduction was found in each of the CRQ domains of dyspnoea, fatigue, emotional function, and mastery (all $\mathrm{p}<0.0001$; fig 2 ). The analysis showed a significant effect of time for the CRQ domains of dyspnoea $(p=0.02)$ and mastery $(p=0.0002)$, but not for fatigue $(p=0.84)$ or emotional function $(p=0.45)$. The significant time effects in the dyspnoea and mastery domains
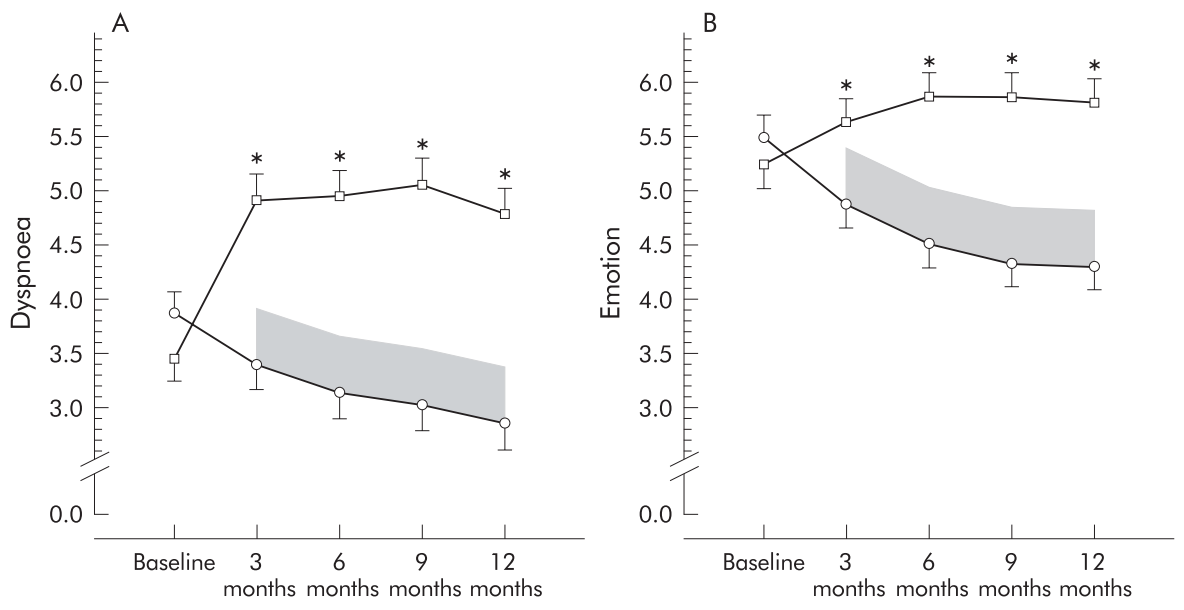

Figure 2 (A-D) Effect of surgery $\square$ ) and medical control treatment (O) on each of the four domains of the $C R Q$ (dyspnoea, emotional function, fatigue, and mastery) at baseline and $3,6,9$, and 12 months after randomisation. Values at follow up are adjusted least square mean (SE). The shaded area shows the minimum clinically important difference for each measure.

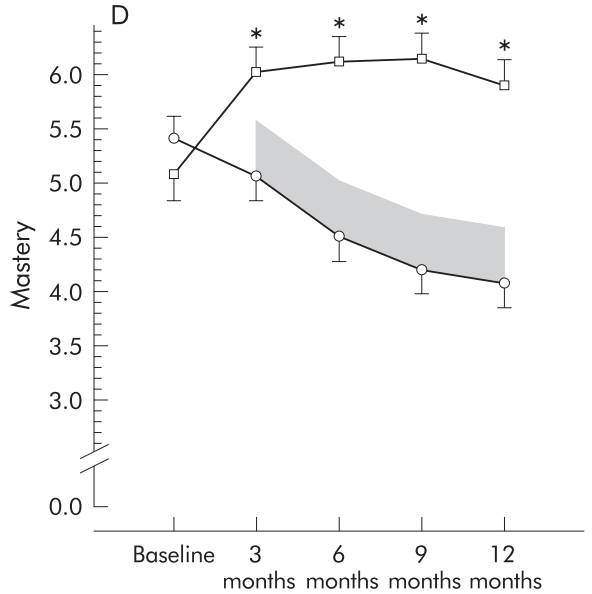




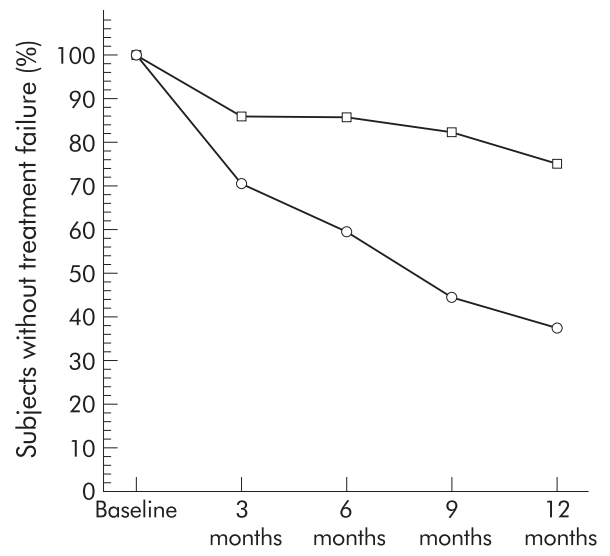

Figure 3 Treatment failure curves for the postoperative $(\square)$ and medical control (O) groups. The $x$ axis shows time after randomisation and the $y$ axis shows the percentage of individuals who did not experience either death, missing data from a treatment complication, or a consistent decrease of $>1.0$ in at least two domains of the CRQ from which they did not recover. Subjects in whom the $C R Q$ decreased by $>1$ but improved at the next visit were not identified as treatment failures while those in whom the CRQ decreased on their last (12 month) visit are identified as treatment failures. Designation from the previous visit was used to substitute for "missing data" unrelated to a treatment complication.

were due to a deterioration in HRQL over the 1 year follow up in the control group (fig 2 ). The analysis also revealed a significant interaction between treatment and time for the CRQ domains of fatigue $(p=0.02)$, emotion $(p=0.01)$, and mastery $(p=0.0005)$, but not dyspnoea $(p=0.10)$. The interaction term was positive in the fatigue, emotion, and mastery domains because the treatment effect increased over the first 9 months of follow up and levelled off at that point (the effect at 9 and 12 months was very similar in all three domains, fig 2).

The magnitude of the effect was greater than the minimal important difference of 0.5 in all domains ${ }^{22}$ even at 3 months and corresponded to very large differences $(>1.5)$ at 9 and 12 months. The differences between groups at 12 months with 95\% confidence intervals (CI) were as follows (all p values $<0.0001$ ): dyspnoea 1.9 (1.3 to 2.6); emotional function 1.5 (0.9 to 2.1 ); fatigue 2.0 ( 1.4 to 2.6 ); mastery 1.8 ( 1.2 to 2.5 ).

Surgical treatment had a large and significant effect (hazard ratio 3.1 (95\% CI 1.3 to 7.6$) ; p=0.01$ ) in preventing treatment failure over 12 months (fig 3 ), which occurred in seven of 28 (25\%) postoperative patients and 17 of 27 (63\%) control patients. The surgical subjects who experienced a postoperative fall in HRQL (including death) had a lower baseline TLCo (difference $-12 \%$ predicted ( $95 \%$ CI -23 to -1 ); p $=0.05$ ) and lower 6 minute walking distance (difference -99 metres $(95 \% \mathrm{CI}-170$ to -27$) ; \mathrm{p}=0.05$ ) than those who did not, with no other baseline differences in HRQL, lung volumes, expiratory flows, arterial blood gas tensions, age, or body mass index.

\section{Secondary outcomes}

There was a significant interaction between treatment and time for TLC $(p=0.05)$ and a significant treatment effect for TLC $(p=0.002)$, FRC $(p=0.005)$, and RV $(p<0.0001)$ with reductions in hyperinflation in the surgically treated group (table 2). There was also a significant treatment effect $(\mathrm{p}=0.0002)$ and time effect $(\mathrm{p}<0.0001)$ for $\mathrm{FEV}_{1}$ with between group differences that were statistically significant and exceeded the minimal important difference for $\mathrm{FEV}_{1}$ in this patient population. ${ }^{23}$ There were significant between group differences in MIP at 3 and 6 months and significant and clinically important between group differences in the 6 minute walk distance at 6,9 and 12 months (table 2) with dif- ferences in excess of the minimal important difference of 57 metres. ${ }^{24}$ Submaximal exercise in the surgical and control groups was similar at baseline (6.9 min (95\% CI 4.5 to 9.3) and 6.6 min (95\% CI 4.7 to 8.4 ), respectively) with significant between group differences being maintained at 12 months ( $7.3 \mathrm{~min}$ (95\% CI 3.9 to 10.8); p<0.0001). Graded exercise was similar at baseline in the surgical ( $37 \mathrm{~W}$ (95\% CI 32 to 42$)$ ) and control groups ( $34 \mathrm{~W}$ (95\% CI 28 to 39)), with significant between group differences at 6 months $(13 \mathrm{~W}(95 \%$ CI 6 to 20); $\mathrm{p}=0.0003$ ).

In the treatment group subsequent comparison between those who underwent bilateral LVRS and those who underwent unilateral LVRS did not identify between group differences for any of the primary or secondary outcome measures at baseline or following surgery.

\section{DISCUSSION}

Despite initial enthusiasm for LVRS, most surgical trials have been uncontrolled ${ }^{25}$ with varied complication rates and insufficient safety or efficacy data to support widespread application of this procedure pending the results of clinical trials that provide conclusive evidence of efficacy and acceptable complication rates. ${ }^{26}$ Fundamental questions remain regarding the longer term benefits over rehabilitation, ${ }^{12}$ optimum selection criteria, the most appropriate outcome measures, the mechanisms of improvement, and the best surgical techniques.

Geddes noted that emphysema was more diffusely distributed in five of 19 surgically treated patients who had no benefit after LVRS than in those who did well, and the NETTRG reported that homogeneous emphysema contributed to the high 30 day study mortality. Individuals with heterogeneous emphysema are more likely to derive benefit from LVRS than those in whom emphysema is homogeneously distributed. ${ }^{27-29}$ This is the first report in which only subjects with heterogeneous disease were enrolled.

Improvements in pulmonary function in our postoperative subjects were consistent with reports that LVRS causes a postoperative diminution in RV with lesser reductions in FRC and TLC. $^{30}$ Postoperative functional outcome depends on dynamic changes in volumes and flows as well as ventilatory requirement and expiratory mechanics. Given that changes in lung function correlate weakly with HRQL, the latter should be measured directly using scales that are valid, responsive, and interpretable. ${ }^{32}$

Although generic health profiles used in previous trials ${ }^{14}$ measure a wide range of aspects of health status, they have limited responsiveness and interpretability making it difficult for health professionals to identify the magnitude of a treatment effect. ${ }^{14}$ We therefore selected a disease specific questionnaire directly relevant to COPD with validity, responsiveness, and interpretability characteristics that are well known, so that the user can distinguish between trivial and important changes in outcome. This study extended previous observations on LVRS by enabling health professionals to distinguish between minimal, moderate and important differences between groups. As it turned out, the effect of surgery on HRQL was large, robust, and persistent. For instance, the lower boundary of the confidence interval around the effect of surgery on dyspnoea in daily living at 12 months was 1.3, more than twice the minimal important difference of 0.5.

Methodological considerations of this study include the absence of a sham surgical group which therefore does not allow us completely to rule out a placebo component in subjects who believed that they should feel better after surgery or who might try harder on their subsequent exercise evaluation, although the consistent changes in pulmonary function could not have been influenced by these beliefs. It is also unlikely that subjects might have answered differently to questions across all domains including emotional function, 
fatigue, dyspnoea, and mastery. Another methodological consideration is that a larger sample size would be required to provide meaningful conclusions regarding mortality between the two groups (four deaths versus one).

Given that the role of LVRS is to enable patients with COPD to feel better, its success among survivors must be interpreted within the context of treatment failures. Deaths alone would not capture this information, although there were only two deaths within 30 days of surgery, a mortality rate consistent with that reported from 42 European centres. ${ }^{33}$ While we consider improvement in quality of life as the primary potential benefit of LVRS, consideration of only quality of life scores is likely to present a biased picture of the impact of LVRS. Perioperative deaths might have occurred in patients who, had they been allocated to the control group, would have deteriorated in the absence of surgery. Removing such patients in the postoperative group through surgical mortality might have resulted in a better outcome profile among surgical survivors than that of the medically treated group.

We addressed this issue using the temporal pattern of a combined outcome of death or functional decline in the two groups. We chose a moderate clinically important difference ( 1 unit of the CRQ) as one likely to result in consideration of LVRS as a treatment strategy. Differences in the combined end point HRQL between the two groups were apparent at 3 months (fig 3). Subsequently, the control group declined at a faster rate than the postoperative group so that by 12 months the two groups were strikingly different, notwithstanding that the decline in the postoperative group included the four subjects who died as well as one subject who was still receiving mechanical ventilation at 3 months and therefore did not attend for follow up at 6 or 9 months.

Questions remain regarding the ideal selection criteria, the role of rehabilitation after surgery, the optimum location and volume of lung to be resected, and the longer term outcome of patients undergoing LVRS. This study confirms the findings of others ${ }^{31} 1434$ with regard to improvement in pulmonary function and extends them by including only those patients with heterogeneous emphysema as well as using a disease specific outcome measure that established a large robust improvement in HRQL. The balance for patients with severe but stable heterogeneous emphysema is between the small risk of an early surgical death or major complication and the longer term benefit in quality of life.

\section{ACKNOWLEDGEMENTS}

Support was provided by the Physician's Services Incorporated Foundation (Ontario Canada), West Park Healthcare Centre, and Mr C Parfet.

\section{Authors' affiliations}

R S Goldstein, T E Dolmage, S van Rooy, B Krip, S Pakhale, West Park Healthcare Centre, University Health Network, University of Toronto, Toronto, Ontario, Canada

R S Goldstein, T R J Todd, S Keshaviee, T K Waddell, Lung Volume Reduction Surgery Clinic, University Health Network, University of Toronto, Toronto

G Guyatt, McMaster University Health Sciences Centre, Hamilton, Ontario, Canada

F Maltais, P LeBlanc, Hopital Laval, Sainte-Foy, Quebec, Canada

\section{REFERENCES}

1 Benditt JO, Wood DE, McCool FD, et al. Changes in breathing and ventilatory muscle recruitment patterns induced by lung volume reduction surgery. Am J Respir Crit Care Med 1997:155:279-84.

2 Argenziano M, Moazami N, Thomashow B, et al. Extended indications for lung volume reduction surgery in advanced emphysema. Ann Thorac Surg 1996;62:1588-97.
3 Cooper JD, Patterson GA, Sundaresan RS, et al. Results of 150 consecutive bilateral lung volume reduction procedures in patients with severe emphysema. J Thorac Cardiovasc Surg 1996;1 12:1319-29. discussion 1329-30.

4 McKenna RJ Jr., Brenner M, Fischel R, et al. Patient selection criteria for lung volume reduction surgery. J Thorac Cardiovasc Surg 1997:114:957-64; discussion 964-7.

5 Mead J, Turner JM, Macklem PT, et al. Significance of the relationship between lung recoil amd maximum expiratory flow. J Appl Physiol 1967;22:95-108.

6 Sciurba FC, Rogers RM, Kennan RJ, et al. Improvement in pulmonary function and elastic recoil after lung reduction surgery for diffuse emphysema. N Engl J Med 1996:334:1095-9.

7 Make BJ, Fein AM. Is volume reduction surgery appropriate in the treatment of emphysema? No. Am J Respir Crit Care Med 1996; 153:1205-7.

8 NETT. Rationale and design of the National Emphysema Treatment Trial (NETT): a prospective randomized trial of lung volume reduction surgery. J Thorac Cardiovasc Surg 1999;1 18:518-28.

9 Benditt JO, Albert RK. Lung reduction surgery. Great expectations and a cautionary note. Chest 1995; 107:297-8.

10 Cutaia M. Lung reduction surgery. Where are we heading? Chest 1996; 109:866-9.

11 Tonelli MR, Benditt JO, Albert RK. Clinical experimentation. Lessons from lung volume reduction surgery. Chest 1996;1 10:230-8.

12 Pompeo E, Marino M, Nofroni I, et al. Reduction pneumoplasty versus respiratory rehabilitation in severe emphysema: a randomized study. Pulmonary Emphysema Research Group. Ann Thorac Surg 2000;70:948-53; discussion 954

13 Criner GJ, Cordova FC, Furukawa S, et al. Prospective randomized trial comparing bilateral lung volume reduction surgery to pulmonary rehabilitation in severe chronic obstructive pulmonary disease. Am J rehabilitation in severe chronic obstructive put

14 Geddes D, Davies M, Koyama H, et al. Effect of lung volume reduction surgery in patients with severe emphysema. N Engl J Med 2000;343:239-45.

15 National Emphysema Treatment Trial Research Group. Patients at high risk of death after lung volume reduction surgery. N Engl J Med 2001;345:1075-83.

16 Lacasse Y, Wong E, Guyatt GH, et al. Meta-analysis of respiratory rehabilitation in chronic obstructive pulmonary disease. Lancet 1996;348: $1115-9$.

17 American Thoracic Society. Standards for the diagnosis and care of patients with chronic obstructive pulmonary disease. Am J Respir Crit Care Med 1995;152:S77-121.

18 American Thoracic Society. Single breath carbon monoxide diffusing capacity (transfer factor). Recommendations for a standard technique-1995 update. Am J Respir Crit Care Med 1995;152:218598.

19 Guyatt GH, Pugsley SO, Sullivan M, et al. Effect of encouragement on walking test performance. Thorax 1984;39:818-22.

20 Jones NL. Conduct of the stage 1 test. In: Trumbold C, Ed. Clinical exercise testing. Philadelphia, PA: W B Saunders, 1988: 135-44.

21 Guyatt GH, Berman LB, Townsend $M$, et al. A measure of quality of life for clinical trials in chronic lung disease. Thorax 1987;42:773-8.

22 Jaeschke R, Singer J, Guyatt GH. Measurement of health status. Ascertaining the minimal clinically important difference. Control Clin Trials 1989;10:407-15.

23 Redelmeier DA, Goldstein RS, Min ST, et al. Spirometry and dyspnea in patients with COPD. When small differences mean little. Chest 1996:109:1163-8.

24 Redelmeier DA, Bayoumi AM, Goldstein RS, et al. Interpreting small differences in functional status: the six minute walk test in chornic lung disease patients. Am J Respir Crit Care Med 1987;155:1278-82.

25 Stirling GR, Babidge WJ, Peacock M, et al. Lung volume reduction surgery in emphysema: a systematic review. Ann Thorac Surg 2001;72:641-8.

26 Drazen JM. Surgery for emphysema - not for everyone. N Engl J Med 2001;345: 1126-8.

27 Baldwin J. Heterogeneity index predicts beneficial outcome in lung volume surgery. Eur Respir J 1997; 10:270-1s

28 Flaherty KR, Kazerooni EA, Curtis JL, et al. Short term and long term outcomes after bilateral lung volume reduction surgery: prediction by quantitative CT. Chest 2001;119:1337-46.

29 Gelb AF, McKenna RJ Jr, Brenner M, et al. Lung function 5 years after lung volume reduction surgery for emphysema. Am J Respir Crit Care Med 2001; 163:1562-6.

30 Utz JP, Hubmayr RD, Deschamps C. Lung volume reduction surgery for emphysema: out on a limb without a NETT. Mayo Clin Proc 1998;73:552-66.

31 Hamacher J, Buchi S, Georgescu CL, et al. Improved quality of life after lung volume reduction surgery. Eur Respir J 2002;19:54-60.

32 Lacasse Y, Guyatt GH, Goldstein RS. Health status measurement instruments in chronic obstructive pulmonary disease. Can Respir J 1997;4:152-64.

33 Hamacher J, Russi EW, Weder W. Lung volume reduction surgery: a survey on the European experience. Chest 2000;11 17:1560-7.

34 Gelb AF, Brenner M, McKenna RJ Jr, et al. Lung function 12 months following emphysema resection. Chest 1996;1 10:1407-15. 